\title{
The Causal Relationship between Eating Animals and Viral Epidemics
}

\author{
Bhaskara L. Reddy ${ }^{a}$ Milton H., Jr. Saier ${ }^{a}$ \\ a Division of Biological Sciences, Department of Molecular Biology, University of California at San Diego, La Jolla, CA, USA
}

\begin{abstract}
Keywords
Viral diseases - Viral transmission · Animal consumption and use - Dietary restrictions - Coronaviruses $\cdot$ Prion diseases
\end{abstract}

\begin{abstract}
For decades it has been known that infectious agents including pathogenic protozoans, bacteria, and viruses, adapted to a particular animal host, can mutate to gain the ability to infect another host, and the mechanisms involved have been studied in great detail. Although an infectious agent in one animal can alter its host range with relative ease, no example of a plant virus changing its host organism to an animal has been documented. One prevalent pathway for the transmission of infectious agents between hosts involves ingestion of the flesh of one organism by another. In this article we document numerous examples of viral and prion diseases transmitted by eating animals. We suggest that the occurrence of cross-species viral epidemics can be substantially reduced by shifting to a more vegetarian diet and enforcing stricter laws that ban the slaughter and trade of wild and endangered species.

(c) 2020 S. Karger AG, Basel
\end{abstract}

\section{Introduction}

Viruses, the living dead, are the greatest villains in a "no man's land" although they are also vehicles of gene transfer and can thereby promote host evolution. For millions of years, we have been at war with these zombie particles along with other pathogens. It is not just our naive immune systems that learn lessons from the pathogens - they learn from us too. Viruses, particularly RNA viruses, such as severe acute respiratory syndrome (SARS), Middle East Respiratory Syndrome (MERS), and SARS-CoV-2 as well as influenza A and B, have extraordinary abilities to mutate, changing their genes and thereby jumping the species barrier to expand their range of victims. RNA viruses do so at much greater rates than DNA viruses [Wang et al., 2018]. Thus, the generation of variants with altered species infectivity is likely to go on long into the future.

Eating habits of humans have not only caused preventable epidemics but they have caused an array of ailments in every one of our body systems [Muyembe-Tamfum et al., 2012]. Environmental sustainability can be achieved in part through eating plants instead of animals [Lăcătușu et al., 2019]. Certainly we eat far more animal products than is good for us, and consuming much less meat of better quality from sustainable sources is highly recommended by most nutritionists and environmentalists. Plants, fungi, and bacteria have all the good things nature has to offer us, and there may be good reasons why these organisms seem to lack pain receptors. Major religious, philosophical, cultural. and scientific groups around the world are convinced that we should respect animal life, but animals are still slaughtered for the food eaten by billions of people. Western nations use stunning methods (the bolt, gassing, and electrocution) so that the animal is unable to display outward signs of pain, but we cannot karger@karger.com

(c) 2020 S. Karger AG, Basel

www.karger.com/mip

Karger"
Milton H. Saier Jr.

Division of Biological Sciences, Department of Molecular Biology

University of California at San Diego, 9500 Gilman Dr. \#0116

La Jolla, CA 92093-0116 (USA)

msaier@ucsd.edu 
prove that the stunned animal does not suffer [Aghwan and Regenstein, 2019]. When an animal is slaughtered with a cut to their neck without stunning, they are believed to feel pain for 12-90 s, depending on the size of the animal. But this is not really known, and there is no truly humane way to kill a sensitive animal.

What are the causes of epidemics, past, present, and future? Undoubtedly, a major one is that we have chosen to live with them rather than to eliminate them [Yang et al., 2020]. In the sections below, we shall describe some of the recent epidemics and pandemics that have disrupted, are disrupting, and will continue to disrupt our congenial lifestyles. We shall provide solutions that each of us can choose to abide by in order to dramatically reduce the consequences of many kinds of transmissible viral (and prion) diseases while improving our lives, minimizing our morbidities, and extending our lifespans.

\section{Severe Acute Respiratory Syndrome}

Over $75 \%$ of emerging infectious diseases are zoonotic [Taylor et al., 2001]. SARS, which caused the 2002 epidemic, was caused by a coronavirus, i.e., SARS-CoV. It arose in Guangdong Province, China, infecting some 5,000 people with a case fatality ratio of $6.4 \%$. Subsequently, the overall fatality rate in several other less well-prepared countries was found to be as high as 15\% [Cao et al., 2011]. The majority of the patients in the initial stages of infection were known to have lived near produce markets, and as many as $40 \%$ of early CoV patients were food handlers with extensive exposure to animals [Xu et al., 2004]. The virus was traced to a palm civet (Panguma larvata), a raccoon dog (Nyctereutes procyonoides), a Chinese ferretbadger (Melogale moschata), and humans working in live animal markets in the Shenzen municipality [Guan et al., 2003]. There is little doubt that the virus jumped from bats to the other animals mentioned above and then to humans as a result of the direct contact of people with the latter animals, in many cases because these animals served as a significant source of nutrition for the local populations.

\section{Middle East Respiratory Syndrome}

Coronaviruses (CoVs), associated with the respiratory, enteric, and nervous systems of birds, mammals, and humans, were believed to cause only occasional lower respiratory infections and pneumonia until we encountered SARS-CoV in 2002. A decade after the SARS epidemic, in
2012, a novel corona virus appeared in Saudi Arabia and was designated the MERS. Overall, it had a higher fatality rate $(\sim 35 \%)$ than SARS. Bats were again found to have provided initial reservoirs of MERS-CoV, but humans were most likely infected through an intermediate host, possibly the camel [Singh, 2016]. Pathogenicity and progression to respiratory failure were reported to be faster in MERS-CoV than in SARS-CoV. The intermediate hosts have been mostly confined to Middle Eastern regions, and this virus may have a lower human-to-human transmission rate, which could explain the lower pandemic potential of MERS-CoV compared to SARS-CoV.

\section{Corona Virus SARS-CoV-2}

The current (May 25, 2020) COVID-19 pandemic, with over 5.5 million cases worldwide and an estimated overall fatality rate of $16 \%$ (deaths/recoveries), and one-third of all cases with an almost 2 -fold higher fatality rate occurring in the USA, was and is caused by a novel coronavirus closely related to SARS-CoV and therefore called SARS-CoV-2 or merely $\mathrm{CoV}-2$. The appearance of this novel virus provides a clear indication that mutations in SARS-like coronaviruses, circulating in bat and other animal populations around the world, threaten to cause more severe pandemics in the future [Xie and Chen, 2020]. Since there is no currently effective treatment or vaccine for any of these coronaviral diseases, even after 18 years of research on SARS, we can anticipate that cures and vaccines for this new virus will not be easily or quickly developed. Newly appearing viruses of this and other types are likely to adapt to humans in the future as the populations of all wild animals decrease, while the human population continues to increase and disturb the natural populations of $\mathrm{CoV}$-carrying animals [Fung et al., 2020]. Because the viral spike (S) protein that binds the cell surface human receptor, i.e., the ACE2 protein, is important for species and organ specificity, it may prove to be the most important viral protein against which an antibody vaccine will be developed.

The Chinese government reported undiagnosed pneumonia cases in Wuhan Province in late December 2019, and the first patients with this novel CoV-2 infection were diagnosed in January 2020. Subsequent investigations revealed that many of the population that developed COVID-19 had purchased animals from the Wuhan wet market and, consequently, it may have been the initial source of the virus [Lam et al., 2020]. Subsequent investigations revealed that crowded wet markets have facilitated the spread of the virus [Decaro et al., 2020]. Similar 
to other virulent human coronaviruses (HCoVs), SARSCoV-2 clearly had an animal origin, likely descended from a bat and transferred to some of the animals sold at the Wuhan market. Both bats and these animals provide reservoirs for the virus, but how widely they are spread throughout the world is not known.

The genome of SARS-CoV-2 was found to be similar not only to bat coronaviruses but also to coronaviruses present in wild pangolins smuggled into China from Malaysia in 2017. These animals may in fact be the intermediate coronaviral hosts that caused the initial outbreak of COVID-19 in Wuhan [Lam et al., 2020]. In the cases of coronaviruses, the viral surface protein that is usually altered when changing a host or host range is the large receptor-binding outer envelope $S$ protein referred to above [Peck et al., 2015].

\section{Ebola Virus}

Three species of fruit bats (Hypsignathus monstrosus, Epomops franqueti, and Myonycteris torquata) are wild reservoirs of Ebola virus Zaire (EBOVZ) [Leroy et al., 2005]. Ebola is an unusual, highly transmissible virus that causes one of the most fatal infections known to plague humans and nonhuman primates. Again, human infection may have initially occurred through direct contact with an animal reservoir or its meat, and this can occur when hunting and preparing "bush meat" (the flesh of nonhuman primates or other wild animals). Once transmitted to humans, it can be spread via contact with bodily fluids from an infected person or, in some cases, by mere person-to-person association, depending on the stability of the virus outside of the body. Hunting and capturing infected animals for bush meat or for trading in the black market as exotic pets have been shown to result in exposure to and transmission of Ebola [Nkangu et al., 2017].

There have been numerous instances of human Ebola infections resulting from contact with dead primates [Bonwitt et al., 2018]. Since the Ebola virus was discovered in 1976, over 28,000 people were infected in West Africa alone, just during the 2014-2016 outbreak, and about 11,000 people died from this viral infection.

\section{Marburg Virus}

The Marburg virus (MARV), like the Ebola virus, is an enveloped RNA filovirus that causes hemorrhagic fever, a fatally infectious disease [Shifflett and Marzi,
2019]. Marburg virus disease is another zoonotic disease that is known to persist in a healthy reservoir identified as the Egyptian fruit bat (Rousettus aegyptiacus). Like the Ebola virus, it infects nonhuman primates as well as humans. The first known human infections were identified in Marburg and Frankfurt, Germany, as well as in Belgrade, Yugoslavia (now Serbia), in 1967. The source of infection was traced to an African green monkey, i.e., Chlorocebus aethiops [Luby and Sanders, 1969]. Once again, contact with and/or ingestion of wild animal meat appears to have been responsible for transmission of the virus to the human population. Given the high rates of mutation that these viruses exhibit, it seems likely that alteration or expansion of a virus's host range, allowing recognition of different receptors on a host cell surface, probably was responsible for the shift. It follows that such alterations could result in novel pandemics in the future.

\section{Human Immunodeficiency Viruses HIV-1 and HIV-2}

Human immunodeficiency viruses, types 1 and 2 (HIV-1 and HIV-2), which cause acquired immunodeficiency syndrome (AIDS), are RNA-enveloped lentiviruses. They infect humans through cross-species transmission of simian immunodeficiency viruses (SIV) from other primates [Sharp and Hahn, 2011]. SIVcpz was believed to have transferred to humans as a result of chimps (Pan troglodytes, our closest primate relative) being killed and eaten by humans, but if chimp blood is exposed to cuts and other wounds on the people hunting these animals, the virus can also be transmitted without ingestion [Sharp and Hahn, 2011]. HIV-2 is believed to have come from SIVsmm of the sooty mangabey (Cercocebus atys), an Old World monkey, found in the forests of Senegal as well as in a margin along the African coast [Chen et al., 1997]. Thus, transmission to humans probably occurred primarily in the same way, through butchering and consumption of monkey meat. African markets are known to have increased the supply of bush meat whenever fish supplies dwindled and, although the consumption of bush meat is illegal in many African countries, this regulation is difficult to enforce. Thus, the action continues at a very significant risk to the human populations in this region of the world. Of course, once infectious in a human, the virus can be spread by the transfer of bodily fluids between people. 


\section{Avian Influenza Virus}

Avian influenza refers to the disease caused by infection with avian (bird) influenza (flu) type A viruses (AIV-A). These viruses occur naturally among wild aquatic birds worldwide and can infect domestic poultry as well as wild birds and other animal species including humans. Avian flu viruses do not normally infect humans, but sporadic human infections caused by these viruses have been reported [Song and Qin, 2020]. AIV is also known as $\mathrm{H} 5 \mathrm{~N} 1$, and this virus has killed billions of poultry in Asia, North Africa, the Middle East, and the Americas. Most recently, it has been found in virtually all countries of the world. It kills between 36 and $60 \%$ of all infected humans and thus has one of the highest case fatality rates.

Cases of H5N1 infections in people were not known until 2017, but transmission to humans is attributed to the fact that the surface proteins of the virus can change due to mutations in the structural genes encoding these proteins. Mutations generate viral forms that are capable of recognizing different host receptors. These viruses aggressively infect domestic birds, wild ducks and geese, and other aquatic and migratory birds, spreading the disease around the world, evolving through ongoing mutation and natural selection. These viruses continue to evolve and adapt to multiple reservoir hosts, including humans, and they pose major threats globally to the poultry industry as well as to people [Song and Qin, 2020]. Like swine influenza virus, discussed in the next section, the continuous recombination of viral RNA, going on in our huge domestic flocks and herds, explains why we need to keep making new vaccines each year, and why international cooperation in monitoring the emergence of new strains is so important. This example illustrates why we should scale down meat consumption and pay farmers more per animal raised, thus allowing them to provide space to minimize overcrowding.

\section{Swine Influenza Virus}

Many strains of influenza virus infect a large array of animal species, including humans, various avian, canine, feline and porcine species, and even marine mammals [ $\mathrm{Li}$ et al., 2015]. Birds are found to be the largest reservoirs of the new strains of flu virus. Pig cells have 2 kinds of receptors, i.e., one targeted by flu viruses that infect humans and another targeted by flu strains that infect birds [Ito et al., 1998]. Therefore, in pigs, different strains of flu viruses can swap their genetic material, creating novel more virulent strains.

Eating Animals Causes Viral Epidemics
China's swine farms are reported to serve as "mixing bowls" for novel influenza viruses [Shortridge et al., 1977]. China is home to some of the largest pig farms in the world, with semi-fenced houses, allowing crowds of wild birds to seek food in the pig pens. Dense populations of humans, pigs, and poultry, all living in close proximity, enable birds carrying avian influenza virus (AIV) to infect pigs and occupational swine-exposed workers [Shu et al., 1996]. An extensive 5-year molecular and immunologic study of 6 Chinese pig farms revealed that a number of swine and human-infected influenza A viruses, similar to $\mathrm{A}(\mathrm{H} 1 \mathrm{N1})$ pdm09-like viruses, were circulating in farms and moving back and forth between humans and pigs [Ma et al., 2018]. The authors also noted that poor farm biosecurity and poor personal hygiene may have contributed to human infections.

$\mathrm{A}(\mathrm{H} 1 \mathrm{N1}) \mathrm{pdm} 09$-like viruses have spread to humans in several countries around the world. Infected people then introduced the virus back into pigs, facilitated by the movement of live pigs in trade [Nelson et al., 2017]. H9N2 AIV infection in large high-density pig herds and a pig farm staff in the Shandong region was similarly reported [ $\mathrm{Li}$ et al., 2015]. Nasal swabs collected from 1,029 healthy pigs revealed 8 H1N1-like viruses in China [Zhao et al., 2012]. Another study of 37,213 pigs in Southern China yielded 387 IAV, with at least 17 unique reassortment genotypes of H1N1-like viruses among them [Liang et al., 2014].

Since the first global epidemic nearly 50 years ago, H1N1 and its reassorted serotypes killed thousands of people around the world, but it is believed that the "Spanish flu" pandemic of 1918 was caused by an H1N1-like virus of mammalian origin that acquired the hemagglutinin gene from an AIV. However, a bacterial pneumonia, caused by Streptococcus pneumoniae, contributed substantially to the high death rate. A third of the world's population was infected during this epidemic that killed over 50 million people worldwide and an estimated 675,000 people in the USA [Johnson and Mueller, 2002]. The Asian pandemic of 1957 was caused by a new influenza A (H2N2) virus that emerged in East Asia, killing an estimated 1.1 million people worldwide, with 116,000 fatalities in the USA [Glezen, 1996]. The Hong Kong pandemic of 1968 occurred with the emergence of influenza A (H3N2), which is a hybrid strain that evolved from $\mathrm{H} 2 \mathrm{~N} 2$, through an antigenic shift, where several subtypes reassorted to form the new virus. The Hong Kong virus came to the USA in 1968, and similar viruses returned in 1970 and 1972, causing over 100,000 deaths. The 1957 Asian flu, the 1968 Hong Kong flu, and the 1977 Russian flu all originated in China [Qin et al., 2018]. 


\section{Prion Diseases}

Prion diseases generally are believed to have arisen from rare, zoonotic, transmissible protein mutations. A prion protein can fold in 2 ways, i.e., into a normal form and a prion form. The prion protein can then influence other similar proteins to fold into the prion form. Patients develop aggressive personality changes, memory loss, problems walking, and other often fatal neurodegenerative disorders, some of which are known as transmissible spongiform encephalopathies. These diseases affect humans and animals, and they include scrapie (in sheep), chronic wasting disease (CWD in deer and elk), bovine spongiform encephalopathy (BSE in cattle), and Creutzfeldt-Jacob disease (CJD in humans). Prion diseases can be inherited due to germ-line mutations in various genes, including the gene encoding the PRNP protein, and it can be acquired through infection with animal or human prions via various routes.

As noted above, scrapie is a prion disease in sheep, first reported in 1732 in the UK; it had a devastating effect on the wool industry, but no known human infections resulted by transfer from the sheep. In the early 1900s, cattle feed manufacturers started supplying farmers who fed their cows with meat bone meal made with discarded bones and internal organs of slaughtered cows and sheep. Farmers in other European countries and the USA soon adopted this practice as it increased the growth rates of the animals. This may have been the origin of BSE, first, involving the spread of this prion disease from sheep to cattle and, second, promoting the spread of the disease throughout the cattle industry.

BSE is a chronic degenerative disease in cows, transforming their brains into "sponges" with neurotic symptoms and paralysis, ultimately leading to death. The World Organization for Animal Health (Office International des Epizooties; OIE) reported 190,628 BSE cases in 25 countries worldwide in August 30, 2012. In the UK, more than 184,000 cases of BSE have been reported, and more than a million cows were destroyed to stop the spread of the disease [Lee et al., 2013]. The occurrence of BSE was dramatically reduced after banning meat bone meal and monitoring animal feed.

It was not suspected that BSE would cross the species barrier and infect humans, but a human variant of BSV was first recognized in 1996 and it was designated variant Creutzfeldt-Jakob disease (vCJD), which is also known as the human form of mad cow disease. Between 1980 and 2000 in the UK and much of Europe, beef consumption was considered risky, fearing a doomsday scenario of mass dementia. BSE appeared first in 1984, and by 1987 scientists had discovered that animal carcasses turned into cattle feed were responsible for the disease. The British Government banned contaminated cow meat and enforced strict safety rules, which saved millions of lives of beef eaters worldwide. Much later, the causative agent was identified as a misfolded self-propagating, posttranslationally modified protein by Stanley Prusinar at the University of California, San Francisco, who was awarded a Nobel Prize in 1997.

Prion proteins in infected animals are concentrated in the brain, eyes, spinal cord, skull, vertebral column, tonsils, and Payer patches of the small intestine. These regions of the body are called "specific risk material." The amount of this risk material required to induce the disease is very small, i.e., as small as a speck of pepper [Lee et al., 2013]. Since such small doses can cause the disease, experiments on prion proteins must be conducted under strictly controlled laboratory conditions.

Payer patches, where the major prion protein $\left(\mathrm{PrP}^{\mathrm{Sc}}\right)$ can be found, are located on the ileum in humans, but in cattle they are found in the whole intestine, including mesenteries [van Keulen et al., 2008]. Therefore, the EU considers the whole intestine as specific risk material. The use of bovine intestines for stuffing sausages and the consumption of bovine intestines in some Asian cultures should be reconsidered. The disease can also be transmitted through the use of surgical instruments and blood transfusions [Lee et al., 2013].

Kuru, a neurodegenerative and infectious "extinct" disease, was the first human prion disease to be recognized, then called a "slow viral disease." It was identified in natives of the South Fore linguistic group in Papua New Guinea in 1920 by the American physician Daniel C. Gajdusek [Collinge, 2008]. The disease is believed to have started in one individual from a spontaneous change that created a pathogenic infectious agent in the brain. This agent was then recycled through the consumption of deceased relatives, spreading the disease in the community and leading to the epidemic [Alpers and Rail, 1971]. Endocannibalism (the eating of relatives) was a common practice as a part of mourning rituals in South Fore [Collinge, 2008]. The proof that kuru was transmitted by cannibalism was provided by Klitzman [2006], who studied clusters of kuru patients, all of whom participated in kuru cannibalism in the 1940s and 1950s. Cannibalism was banned in 1959, and no individual born after 1959 has been diagnosed with kuru [Gajdusek, 1977]. The kuru epidemic killed at least 1,874 individuals, predominantly in the South Fore population of Papua New Guinea. The similarities between kuru and scrapie were recognized quite early, but it was not until 2015 that they were both shown to be prion diseases [Jaunmuktane et al., 2015]. 


\section{Conclusion}

SARS spread to 29 countries around the world in 8 months, infecting about 8,100 people, with a fatality rate of $\sim 15 \%$. MERS infected 2,494 people in 27 countries, with a fatality rate of roughly $35 \%$. Covid-19 cases exceeded 5.5 million as of May 25, 2020, spreading from a very few cases to this number in just over 4 months. The initial fatality rate (fatalities/cases) in China was $\sim 6 \%$, although this rate has declined as the disease has spread throughout China, and then worldwide, in part, because health care professionals learned how to deal more effectively with the disease. Nevertheless, fatalities are still occurring at a high rate, with over 4,000 deaths reported per day worldwide. Thus, although the fatality rate from Covid-19 (in percentages of cases) is less than those due to SARS and MERS, the transmission rate between humans seems to be far greater than for the other 2 human respiratory coronavirus diseases, with about 100,000 new cases reported per day.

There has been extensive research on animal CoVs in veterinary medicine. The pathogenicity and evolution of infectious bronchitis virus (IBV) in poultry, feline infectious peritonitis virus (FIPV) in cats, and transmissible gastroenteritis virus (TGEV) in swine, to mention a few, have been known in veterinary medicine since the beginning of the twentieth century [Decaro et al., 2020]. Studies of animal coronaviruses have provided evidence as to how these viruses evolve, changing tissue tropism and virulence and crossing the species barriers to infect new hosts [Decaro et al., 2020]. Swine TGEV likely originated from the related canine coronavirus (CCoV) [Lorusso et al., 2009]; the less virulent porcine respiratory coronavirus ( $\mathrm{PRCoV}$ ) may then have originated from TGEV, and a TGEV-like CCoV may have been generated by a nucleic acid recombination event, changing the $\mathrm{N}$-terminus of the viral S protein [Decaro et al., 2009]. The $\beta$-coronaviral porcine hemagglutinating encephalomyelitis virus (PHEV) was a derivative of a bovine coronavirus, which, in turn, is believed to have evolved from a bat virus, adapted to a rodent species [MoraDiaz et al., 2019]. Animal coronaviruses' ability to jump species barriers repeatedly is proof of their exceptional ability to adapt by expansion or alteration of their host ranges.

We can expect far more serious epidemics and pandemics in the near future, as many viral and other pathogenic vectors are made homeless due to the loss of virtually all wild animals, resulting from hunting, deforestation, environmental degradation, and anthropization. Human consumption of wild animals has enormously increased the risk of selecting for viral mutations and genetic recombination in the viral genome, allowing adap-

Eating Animals Causes Viral Epidemics tation to humans. Slaughtering of wild animals and consumption of endangered animals should be banned altogether and strictly enforced around the world. Illegal sales of exotic wild animals and their meat are prevalent, even in the USA, and these practices may become sources of future epidemics. The lack of resources to allow testing and inspections and an increased appetite for exotic meat, coupled with economic affluence, is allowing the illegal trade of endangered wild animals to continue, especially in developed countries. With increasing globalization, greater mixing of populations between cities and towns worldwide, and the high transmissibility of viruses within high-density populations, it is not surprising that we can expect unprecedented human catastrophes.

Undoubtedly, Covid-19 will not be the last one. We can only hope that the SARS-CoV-2 pandemic will increase our awareness of emerging viruses so we can take necessary precautions by curbing our craving for exotic meat and discover the rich nutrients in the varieties of seeds, leaves, vegetables, and fruits of the plant world. No known epidemic has resulted from the transmission of a plant virus to an animal. We do not all have to become vegans, but we can easily become predominant vegetarians as appears to have been characteristic of most of our early ancestors. And if we do, we shall live healthier and longer quality lives.

\section{Acknowledgement}

The authors thank Prof. Steve Baird, Prof. Steve Hedrick, Prof. Justin Meyer, and Prof. Ralf Rabus for critically reading this paper and providing valuable suggestions before submission for publication.

\section{Conflict of Interest Statement}

The authors have no conflict of interests to declare. One of the authors (M.H.S.) is an editor-in-chief of Microbial Physiology.

\section{Funding Sources}

This work was supported by grant GM077402 to M.H.S. from the National Institutes of Health (https://www.nih.gov/). The funders had no role in the study design, data collection and analysis, the decision to publish, or the preparation of this paper.

\section{Author Contributions}

Both B.L.R. and M.H.S. contributed to the conception of this project, performed research, and drafted and approved this work for publication. 


\section{References}

Aghwan ZA, Regenstein JM. Slaughter practices of different faiths in different countries. J Anim Sci Technol. 2019 May;61(3):111-21.

Alpers M, Rail L. Kuru and Creutzfeldt-Jakob disease: clinical and aetiological aspects. Proc Aust Assoc Neurol. 1971;8:7-15.

Bonwitt J, Dawson M, Kandeh M, Ansumana R, Sahr F, Brown H, et al. Unintended consequences of the "bushmeat ban" in West Africa during the 2013-2016 Ebola virus disease epidemic. Soc Sci Med. 2018 Mar;200:166-73.

Cao WC, de Vlas SJ, Richardus JH. The severe acute respiratory syndrome epidemic in mainland China dissected. Infect Dis Rep. $2011 \mathrm{Feb} ; 3(1): \mathrm{e} 2$.

Chen Z, Luckay A, Sodora DL, Telfer P, Reed P, Gettie A, et al. Human immunodeficiency virus type 2 (HIV-2) seroprevalence and characterization of a distinct HIV-2 genetic subtype from the natural range of simian immunodeficiency virus-infected sooty mangabeys. J Virol. 1997 May;71(5):3953-60.

Collinge J. Review. Lessons of kuru research: background to recent studies with some personal reflections. Philos Trans R Soc Lond B Biol Sci. 2008 Nov;363(1510):3689-96.

Decaro N, Mari V, Campolo M, Lorusso A, Camero M, Elia G, et al. Recombinant canine coronaviruses related to transmissible gastroenteritis virus of Swine are circulating in dogs. J Virol. 2009 Feb;83(3):1532-7.

Decaro N, Martella V, Saif LJ, Buonavoglia C. COVID-19 from veterinary medicine and one health perspectives: what animal coronaviruses have taught us. Res Vet Sci. 2020 Aug; 131:21-3.

Fung SY, Yuen KS, Ye ZW, Chan CP, Jin DY. A tugof-war between severe acute respiratory syndrome coronavirus 2 and host antiviral defence: lessons from other pathogenic viruses. Emerg Microbes Infect. 2020 Mar;9(1):558-70.

Gajdusek DC. Unconventional viruses and the origin and disappearance of kuru. Science. 1977 Sep;197(4307):943-60.

Glezen WP. Emerging infections: pandemic influenza. Epidemiol Rev. 1996;18(1):64-76.

Guan Y, Zheng BJ, He YQ, Liu XL, Zhuang ZX, Cheung CL, et al. Isolation and characterization of viruses related to the SARS coronavirus from animals in southern China. Science. 2003 Oct;302(5643):276-8.

Ito T, Couceiro JN, Kelm S, Baum LG, Krauss S, Castrucci MR, et al. Molecular basis for the generation in pigs of influenza A viruses with pandemic potential. J Virol. 1998 Sep;72(9): 7367-73.

Jaunmuktane Z, Mead S, Ellis M, Wadsworth JD, Nicoll AJ, Kenny J, et al. Evidence for human transmission of amyloid- $\beta$ pathology and cerebral amyloid angiopathy. Nature. 2015 Sep; 525(7568):247-50.

Johnson NP, Mueller J. Updating the accounts: global mortality of the 1918-1920 "Spanish" influenza pandemic. Bull Hist Med. 2002; 76(1):105-15
Klitzman RL. Incubation period of human prion disease. Lancet. 2006 Sep;368(9539):913.

Lăcătușu CM, Grigorescu ED, Floria M, Onofriescu A, Mihai BM. The Mediterranean Diet: From an Environment-Driven Food Culture to an Emerging Medical Prescription. Int J Environ Res Public Health. 2019 Mar; 16(6):E942.

Lam TT, Jia N, Zhang YW, Shum MH, Jiang JF, Zhu HC, et al. Identifying SARS-CoV-2-related coronaviruses in Malayan pangolins. Nature. 2020 Jul;583(7815):282-5.

Lee J, Kim SY, Hwang KJ, Ju YR, Woo HJ. Prion diseases as transmissible zoonotic diseases. Osong Public Health Res Perspect. 2013 Feb; 4(1):57-66.

Leroy EM, Kumulungui B, Pourrut X, Rouquet $P$, Hassanin A, Yaba P, et al. Fruit bats as reservoirs of Ebola virus. Nature. 2005 Dec; 438(7068):575-6.

Li S, Zhou Y, Zhao Y, Li W, Song W, Miao Z. Avian influenza H9N2 seroprevalence among pig population and pig farm staff in Shandong, China. Virol J. 2015 Mar;12(1):34.

Liang H, Lam TT, Fan X, Chen X, Zeng Y, Zhou J, et al. Expansion of genotypic diversity and establishment of 2009 H1N1 pandemic-origin internal genes in pigs in China. J Virol. 2014 Sep;88(18):10864-74.

Lorusso A, Desario C, Mari V, Campolo M, Lorusso E, Elia G, et al. Molecular characterization of a canine respiratory coronavirus strain detected in Italy. Virus Res. 2009 Apr;141(1): 96-100.

Luby JP, Sanders CV. Green monkey disease ("Marburg virus" disease): a new zoonosis. Ann Intern Med. 1969 Sep;71(3):657-60.

Ma MJ, Wang GL, Anderson BD, Bi ZQ, Lu B, Wang XJ, et al. Evidence for Cross-species Influenza A Virus Transmission Within Swine Farms, China: A One Health, Prospective Cohort Study. Clin Infect Dis. 2018 Feb;66(4): 533-40.

Mora-Díaz JC, Piñeyro PE, Houston E, Zimmerman J, Giménez-Lirola LG. Porcine hemagglutinating encephalomyelitis virus: a review. Front Vet Sci. 2019 Feb;6:53.

Muyembe-Tamfum JJ, Mulangu S, Masumu J, Kayembe JM, Kemp A, Paweska JT. Ebola virus outbreaks in Africa: past and present. Onderstepoort J Vet Res. 2012 Jun;79(2):451.

Nelson MI, Culhane MR, Trovão NS, Patnayak DP, Halpin RA, Lin X, et al. The emergence and evolution of influenza $\mathrm{A}(\mathrm{H} 1 \alpha)$ viruses in swine in Canada and the United States. J Gen Virol. 2017 Nov;98(11):2663-75.

Nkangu MN, Olatunde OA, Yaya S. The perspective of gender on the Ebola virus using a risk management and population health framework: a scoping review. Infect Dis Poverty. 2017 Oct;6(1):135.
Peck KM, Burch CL, Heise MT, Baric RS. Coronavirus Host Range Expansion and Middle East Respiratory Syndrome Coronavirus Emergence: Biochemical Mechanisms and Evolutionary Perspectives. Annu Rev Virol. 2015 Nov;2(1):95-117.

Qin Y, Zhao MJ, Tan YY, Li XQ, Zheng JD, Peng $\mathrm{ZB}$, et al. History of influenza pandemics in China during the past century. Zhonghua Liu Xing Bing Xue Za Zhi. 2018 Aug;39(8):102831.

Sharp PM, Hahn BH. Origins of HIV and the AIDS pandemic. Cold Spring Harb Perspect Med. 2011 Sep;1(1):a006841.

Shifflett K, Marzi A. Marburg virus pathogenesis - differences and similarities in humans and animal models. Virol J. 2019 Dec;16(1):165.

Shortridge KF, Webster RG, Butterfield WK, Campbell CH. Persistence of Hong Kong influenza virus variants in pigs. Science. 1977 Jun;196(4297):1454-5.

Shu LL, Zhou NN, Sharp GB, He SQ, Zhang TJ, Zou WW, et al. An epidemiological study of influenza viruses among Chinese farm families with household ducks and pigs. Epidemiol Infect. 1996 Aug;117(1):179-88.

Singh SK. Middle East Respiratory Syndrome Virus Pathogenesis. Semin Respir Crit Care Med. 2016 Aug;37(4):572-7.

Song W, Qin K. Human-infecting influenza A (H9N2) virus: A forgotten potential pandemic strain? Zoonoses Public Health. 2020 May; 67(3):203-12.

Taylor LH, Latham SM, Woolhouse ME. Risk factors for human disease emergence. Philos Trans R Soc Lond B Biol Sci. 2001 Jul; 356(1411):983-9.

van Keulen LJ, Bossers A, van Zijderveld F. TSE pathogenesis in cattle and sheep. Vet Res. 2008 Jul-Aug;39(4):24.

Wang L, Su S, Bi Y, Wong G, Gao GF. Bat-Origin Coronaviruses Expand Their Host Range to Pigs. Trends Microbiol. 2018 Jun;26(6):46670.

Xie M, Chen Q. Insight into 2019 novel coronavirus: an updated interim review and lessons from SARS-CoV and MERS-CoV. Int J Infect Dis. 2020 May;94:119-24.

Xu RH, He JF, Evans MR, Peng GW, Field HE, Yu DW, et al. Epidemiologic clues to SARS origin in China. Emerg Infect Dis. 2004 Jun;10(6): 1030-7.

Yang Y, Peng F, Wang R, Yange M, Guan K, Jiang T, et al. The deadly coronaviruses: the 2003 SARS pandemic and the 2020 novel coronavirus epidemic in China. J Autoimmun. 2020 May; 109:102434.

Zhao G, Fan Q, Zhong L, Li Y, Liu W, Liu X, et al. Isolation and phylogenetic analysis of pandemic H1N1/09 influenza virus from swine in Jiangsu province of China. Res Vet Sci. 2012 Aug;93(1):125-32. 